\title{
Ensaio miniaturizado para a quantificação simultânea de antocianinas em flores de Hibiscus
}

\author{
Luciano da Silva Lima ${ }^{1 *}$, Adriana Santos Rossi ${ }^{1}$; Hênia Joelia Magalhães Cruz¹; Marcus Luciano S. \\ Ferreira Bandeira ${ }^{1}$; Leonardo Dias Nascimento ${ }^{1}$
}

\begin{abstract}
RESUMO: Antocianinas são pigmentos naturais responsáveis por uma variedade de cores observadas em frutos, flores e algumas folhas, caules e raízes de plantas. A quantidade de antocianinas extraída foi medida pelo método diferencial $\mathrm{pH}$, comumente usado em amostras ou em produtos alimentícios. No entanto, essa metodologia clássica demanda grande quantidade de reagentes, amostras e tempo. O presente estudo descreve um ensaio miniaturizado adaptado para a quantificação simultânea de antocianinas em microplaca, substituindo o tradicionalmente utilizado. Este ensaio permitiu análises rápidas, baratas e simultâneas.
\end{abstract}

Palavras-chave: microplacas, método diferencial de $\mathrm{pH}$, pigmentos antociânicos.

\section{Miniaturized assay for simultaneous quantification of anthocyanins in Hibiscus flowers}

\begin{abstract}
Anthocyanins are natural pigments responsible for a variety of colors observed in fruits, flowers and some leaves, stems and roots of plants. The amounts of extracted anthocyanins where measured by $\mathrm{pH}$ differential method, commonly used in samples or food products. However, this classic methodology demands a large amount of reagents, samples and time. The present study describes an adapted miniaturized assay for the simultaneous quantification of anthocyanins in microplate, replacing the traditionally used. This assay allowed rapids analysis, inexpensive and simultaneous.
\end{abstract}

Keywords: microplate, differential $\mathrm{pH}$ method, anthocyanic pigments.

\section{INTRODUÇÃO}

As antocianinas são pigmentos naturais pertencentes à classe dos flavonoides encontrados na maioria dos vegetais, responsáveis pela coloração roxa, violeta, lilás, vinho, vermelho, rosa e demais variações existentes em folhas, frutas, flores, legumes e sementes. Além de serem responsáveis pela coloração nos vegetais, em geral, apresentam diversas propriedades que são associadas a hábitos saudáveis na alimentação, que tem sido atrativa para a indústria alimentícia e farmacêutica (CEDRIM et al., 2018; KHOO, et al., 2017; TEXEIRA et al., 2008).

Com o crescente interesse em novas fontes de antocianinas, impulsionada pelo conhecimento dos inúmeros benefícios ligados a saúde, pesquisas são direcionadas com intuito da descoberta dos pigmentos em vegetais ainda não explorados. Diversas técnicas são descritas para a quantificação de antocianinas em extraídos de vegetais, por exemplo, a Cromatografia Líquida de Alta Eficiência (CLAE) (HONG et al., 2020; GIUSTI et al., 2014; GOUVEIA et al., 2012), Espectrometria de Massas (EM), Eletroforese Capilar (CE) e por espectrofotometria UV-VIS (MARÇO et al., 2008).

Os métodos espectrofotométricos são muito aplicados na determinação e quantificação dos pigmentos antociânicos, sendo o método diferencial de $\mathrm{pH}$ a metodologia considerada oficial pela
Association of Analytical Communities (AOAC) (LEE et al., 2005). Apesar do método de diferencial de $\mathrm{pH}$ apresentar exatidão e baixo custo, ainda apresenta algumas limitações relacionadas a execução das etapas dos procedimentos, o que acarreta gastos excessivos de reagentes e tempo, potencializado com análises de muitas amostras, gerando enorme quantidade de resíduos químicos.

$\mathrm{O}$ presente manuscrito descreve um ensaio rápido miniaturizado em microplacas para a quantificação simultânea de antocianinas em vegetais, resultando na redução da quantidade de amostras, de reagentes e de tempo empregado. A avaliação foi realizada com espécies do Gênero Hibiscus (Malvaceae).

\section{MATERIAL E MÉTODOS \\ Amostragem: Material Vegetal}

As flores usadas no estudo foram das espécies Hibiscus acetosella, Malvaviscus arboreus e quimiótipos de Hibiscus rosa-sinenses (vermelho, amarelo e rosa), coletadas na cidade de Santa Cruz Cabrália, Bahia, Brasil (16¹6 58” S 3901'41” W).

\section{Preparação dos Extratos}

Após secas e moídas, 10 gramas das flores das espécies foram submetidas à extração com $50 \mathrm{~mL}$ de etanol 95\% $(v / v)$ durante 48 horas em temperatura 
ambiente. Os extratos obtidos foram filtrados subseqüentemente através do filtro de papel Whatman no. 2 e a remoção do solvente, foi realizado por destilação em evaporador rotatório, sob pressão reduzida.

\section{Ensaio rápido e miniaturizado para a quantificação em extratos}

A quantificação de antocianinas pelo ensaio $\mathrm{pH}$ diferencial miniaturizado, consistiu na adaptação da metodologia oficial (AOAC) (LEE et al., 2005; LIMA et al., 2007) em microplacas, com leitura espectrofotométrica das absorbâncias em $520 \mathrm{~nm}$ e $700 \mathrm{~nm}$ em pH 1 e pH 4,5.volume de $200 \mu \mathrm{L}$ em tampão. Este ensaio permitiu as leituras simultâneas

das amostras em comparação ao método convencional utilizado em cubetas.

Para o preparo das soluções, 0,1 g dos extratos brutos foram solubilizados em $5 \mathrm{~mL}$ de água destilada e obtido diluição 1 (D1). Diluições de D1 foram realizadas para obter a densidade óptica entre 0,200 1,400 a $520 \mathrm{~nm}$ em microplaca (96 poços), com a adição posterior de tampão de cloreto de potássio ( $\mathrm{KCl} 0,025 \mathrm{~mol} \mathrm{~L}^{-1}, \mathrm{pH} 1,0$ ) e acetato de sódio $\left(\mathrm{CH}_{3} \mathrm{COONa} 0,4 \mathrm{~mol} \mathrm{~L}^{-1}, \mathrm{pH} 4,5\right)$ e obtido diluição 2 (D2). Para a correção dos valores de $\mathrm{pH}$ na solução o ácido clorídrico $\left(1 \mathrm{~mol} \mathrm{~L}^{-1}\right)$ foi empregado.

Após 30 minutos foram realizadas leituras das absorbâncias para cada poço da microplaca contendo o sistema de tampão/amostras em espectrofotômetro (Thermo Scientific Multiskan Go) em 520 e 700nm (Figura 1).

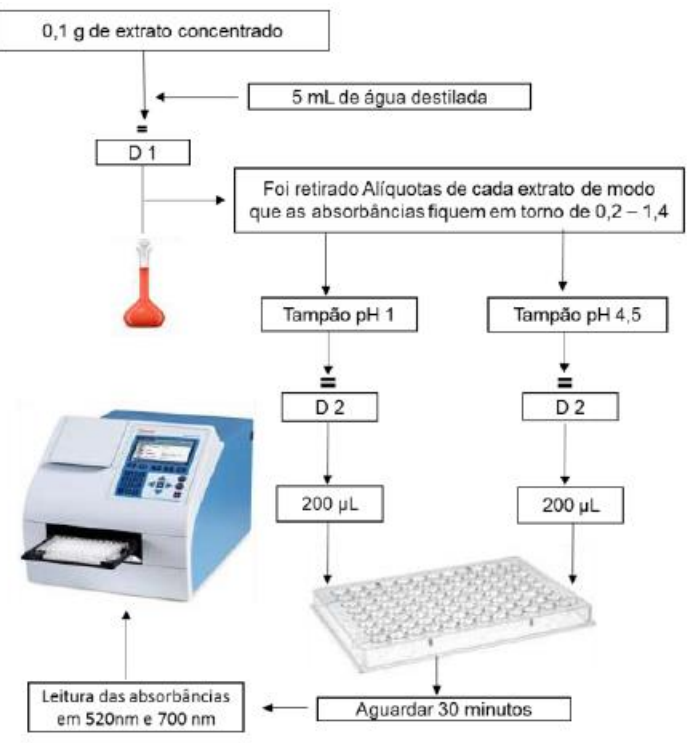

1

Figura 1. Procedimento do ensaio miniaturizado para quantificação de antocianinas em extratos

A absorbância foi calculada a partir da equação 1 e a cianidina-3-glicosídeo foi utilizada como referência para o cálculo da concentração de pigmentos monoméricos, através da equação 2 .

$$
\begin{gathered}
\mathrm{A}=(\text { A 520nm - A 700nm)pH } 1- \\
(\text { A 520nm - A 700nm) pH 4,5 (Equação 1) }
\end{gathered}
$$

Onde: A520 nm e A700 nm são as absorbâncias das respectivas amostras.

$$
\text { Antocianina }(\mathrm{mg} / \mathrm{g})=\frac{A \cdot M M \cdot F D \cdot 1000}{\varepsilon \cdot L} \quad(\text { Equação 2) }
$$

Onde: $\mathrm{A}$ = absorbância; $\mathrm{MM}=$ Massa molar da cianidina-3glicosídeo; FD =fator de diluição, 1000= Fator de correção para expressar resultado em mg. $100 \mathrm{~g}^{-1}, \varepsilon=$ absortividade molar e $\mathrm{L}=$ Caminho óptico.

As antocianinas foram realizadas tambem pelo ensaio convencional em cubetas, considerado o método oficial da AOAC (Association of Analytical
Communities) (LEE et al., 2005), para posterior comparação dos resultados obtidos.

\section{Avaliação Estatística}

A análise comparativa entre os teores de antocianinas pelos ensaios foi realizada por análise de variância (ANOVA) e teste de Tukey ao nível de 5\% de significância, utilizando-se o software Livre PAST, EXCEL (Microsoft $®$ ). Os dados foram demonstrados como média \pm desvio padrão e os gráficos foram plotados com auxílio do Programa $R$ (R CORE TEAM, 2020).

\section{RESULTADOS E DISCUSÃO}

A escolha do solvente na extração desempenha um fator fundamental para adquirir a fração rica e rendimentos maiores no processo extrativo das antocianinas. O etanol foi o escolhido como extrator, com base em alguns estudos, que demonstraram que 
o solvente, é eficaz para a extração de antocianinas de diferentes materiais vegetais (ELE et al., 2016; YUANA et al., 2020).

A extração sólido-líquido é uma das técnicas mais empregadas na extração de antocianinas em vegetais pela eficiência e fácil execução. O processo consiste na imersão do material vegetal em solventes com posterior filtração e concentração do filtrado. Contudo, Durand et al. (2017) apontam como desvantagem a necessidade do emprego de solventes orgânicos e na maioria das vezes apresentam grande toxicidade. Neste trabalho, foram obtidos os rendimentos de extratos para as espécies Hibiscus acetosella $(5,55 \%, \mathrm{~m} / \mathrm{m})$, Malvaviscus arboreus $(4,63 \%, \mathrm{~m} / \mathrm{m})$ e os três tipos de quimiótipos de Hibiscus rosa-sinenses $(5,33 \%, 4,97 \%$ e $3,89 \%$ $\mathrm{m} / \mathrm{m})$.

As médias dos teores de antocianinas pelo ensaio convencional em cubetas e por miniaturizado em microplacas são apresentados na Tabela 1. Nos dois ensaios as médias por $100 \mathrm{~g}$ de amostra apresentaram valores similares. Em ambos, a $H$. acetosella $(1048,1$ $\pm 0,96$ e $1049,58 \pm 0,10 \mathrm{mg} / 100 \mathrm{~g}$ ) apresentou maior concentração dos pigmentos, seguido pelo Malvaviscus arboreus e o menor teor de foi detectado para a Hibiscus rosa-sinenes L. rosa. No entanto, todos os extratos podem ser considerados com elevada concentração de antocianinas, uma vez que apresentaram valores médio dos pigmentos superiores ao limite estabelecido de $200 \mathrm{mg} / 100 \mathrm{~g}$ proposto em Macheix et al. (1990) e Teixeira et al. (2008).

As absorbâncias dos extratos no ensaio em microplaca foram obtidas simultaneamente e os teores foram calculados mediante o uso da Equação 2, e se fez necessário a correção do caminho óptico $(l)$ para $0,50 \mathrm{~cm}$ considerando o diâmetro e volume de $200 \mu \mathrm{L}$ dos poços. O caminho óptico (l) na quantificação de antocianinas pelo método convencional em cubetas foi igual a $1,0 \mathrm{~cm}$.

A correção do ensaio miniaturizado foi baseada no comportamento proporcional da absorbância e do caminho óptico, devido ao aumento do número de espécies absorventes que interagem com o feixe de radiação (MELCHERT et al., 2008), princípio fundamental da lei de Lambert-Beer. Desta forma, diante do comportamento linear das absorbâncias, razões de proporcionalidade entre as absorções foram realizadas para a correção.

\section{Comparação dos ensaios de quantificação de antocianinas}

A média e o desvio padrão para cada amostra indicam que os resultados obtidos para os ensaios são equivalentes, não havendo diferença significativa ao nível de $5 \%$ (Tabela 1 ).

TABELA 1. Teores de antocianinas (mg/100g) em flores Hibiscus obtidos pelos ensaios em cubetas e microplacas

\begin{tabular}{llccc}
\hline \multirow{2}{*}{ Flores } & \multicolumn{3}{c}{ Concentração de antocianinas* } \\
& \multicolumn{3}{c}{$\mathrm{mg} / 100 \mathrm{~g}$} \\
\cline { 2 - 4 } & Ensaio convencional em cubetas & $\% \mathrm{CV}$ & Ensaio miniaturizado em microplacas $\%$ CV & 0,01 \\
H. acetosell & $1048,1 \pm 1,0$ & 0,09 & $1049,58 \pm 0,10$ & 0,02 \\
M. arbóreus & $922,1 \pm 0,5$ & 0,05 & $922,39 \pm 0,19$ & 0,06 \\
H. rosa-sinenses (vermelho) & $849,4 \pm 0,5$ & 0,06 & $848,58 \pm 0,51$ & 0,10 \\
H. rosa-sinenses (amarelo) & $866,4 \pm 0,5$ & 0,06 & $866,00 \pm 0,88$ & 0,13 \\
H. rosa-sinenses (rosa) & $555,8 \pm 0,5$ & 0,09 & $555,96 \pm 0,70$ &
\end{tabular}

*Média \pm Desvio padrão \% CV= coeficiente de variação.

$\mathrm{O}$ coeficiente de variância $(\% \mathrm{CV})$ entre as triplicatas nos extratos das flores foi de 0,05 a 0,09 e 0,01 a $0,13 \%$ para o ensaio convencional em cubetas e do miniaturizado em microplacas, respetivamente, demonstrando boa precisão dos ensaios.
O coeficiente de correlação Person (r) (Figura 2) obtido por meio da regressão linear expressou alto grau de associação entre os ensaios, corroborando a relação estatística entre as variáveis, o que não implica na existência de causa-efeito entre ela. 


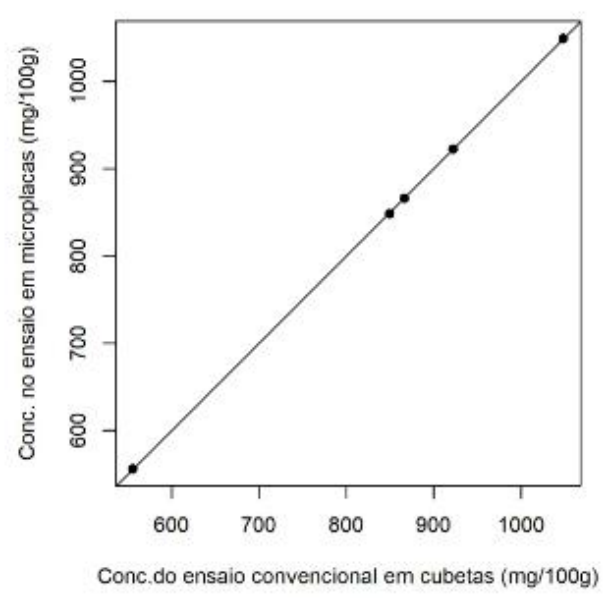

Figura 02: Correlação positiva do coeficiente $(r=0.9999, Y=1.552 x-1,001)$ entre os ensaios

Neste trabalho, foi evidenciado que o ensaio miniaturizado para a quantificação de antocianinas em microplacas permitiu uma análise fácil e rápida de um número grande de amostras em comparação ao tradicionalmente utilizado em cubetas. Além disso, volumes de amostra relativamente pequenos, oferecem vantagens em relação ao volume de reagentes, custos, velocidade das análises e geração de menor quantidade de resíduos, implicando em questões favoráveis para a redução de impactos ambientais refente ao uso de solventes orgâanicos sobre o ambiente e saúde humana, em acordo aos princípios conceito da quíimica verde (LENARDÃO et al.,2003).

Novas releituras de metodologias através de ensaios miniaturizados em microplacas têm recebido grande atenção no âmbito da química verde, por serem considerados potencialmente mais eficientes e ambientalmente mais corretas. Recentemente, Nunes et al. (2019) propôs métodos de ensaios espectrofotométricos adaptados em microplacas para analisar as capacidades antioxidantes de frutas vermelhas e, os ensaios apresentaram diversas vantagens em relação aos tradicionalmente utilizados em cubetas.

\section{CONCLUSÃO}

Os resultados permitem concluir que não existem diferenças significativas entre os ensaios, assim as metodologias podem ser empregadas com sucesso para a quantificação de antocianinas em extratos. No entanto, o ensaio minituarizada em microplacas proposta neste trabalho, se mostra como um protocolo de análise rápida, mais barata, confiável para a quantificação de antocianinas de extratos de fontes vegetais.
Ao CNPq (MCTI/CNPQ/Universal 14/2014Processo 455603/2014-6) e a FAPESB (FAPESBTermo de Outorga RED 0043/2014) pelo suporte financeiro.

\section{REFERÊNCIAS}

CEDRIM, P. C. A. S.; BARROS, E. M. A.; NASCIMENTO, T. G. do. (2018). Propriedades antioxidantes do açaí (Euterpe oleracea) na síndrome metabólica. Brazilian Journal of Food Technology, Campinas, v.21, p. 1-7, 2018.

DURAND E.; ESPINOZA, M. C. F.; DURAND, E. Application of Deep Eutectic Solvents (DES) for Phenolic Compounds Extraction: Overview, Challenges, and Opportunities, Journal of Agricultural and Food Chemistry, v.65, p. 3591-3601, 2017.

ELE, B.; ZHANG, L.L.; YUE, X.; LIANG, J.; JIANG, J.; GAO, X.; YUE, P. Optimization of Ultrasound-Assisted Extraction of phenolic compounds and anthocyanins from blueberry (Vaccinium ashei) wine pomace. Food Chemistry, v.204, p. 70-76, 2016.

GIUSTI, M.; POLIT, M. F.; AYVAZ, H.; TAY, D.; MANRIQUE, I. (2014) Characterization and quantificação of anthocyanins and other phenolic in native andean potatoes. Agricultural and Food Chemistry. v.62, n.19, p.4408-4416, 2014.

GOUVEA, A. M. S.; ARAUJO, M. C. P.; SCHULZ, D. F.; PACHECO, S.; GODOY, R. L. DE O.; CABRAL, L. M. C. Anthocyanins standards (cyanidin-3-O-glucoside and cyanidin-3-O-rutinoside) isolation from freeze-dried açaí (Euterpe oleraceae Mart.) by HPLC. Ciência e Tecnologia de Alimentos, Campinas, v.32, n. 1, p. 43-46, 2012. 
HONG, H. T.; NETZEL, M. E.; O'HARE, T. J. Optimisation of extraction procedure and development of LC-DAD-MS methodology for anthocyanin analysis in anthocyanin-pigmented corn kernels. Food Chemistry, v. 31930, n. 30, p. 1-8, 2020.

KHOO, E. H.; AZLAN, A. A.; TANG, S. T.; LIM, S. M. Anthocyanidins and anthocyanins: colored pigments as food, pharmaceutical ingredients, and the potential health benefits. Food \& Nutrition Research, v.61, p. 1-21, 2017.

LEE, J.; DURST, R. W.; WROLSTAD, R.E. Determination of total monomeric anthocyanin pigment content of fruit juices, beverages, natural colorants, and wines by the $\mathrm{pH}$ differential method: Collaborative Study. Journal of AOAC International, v.88, n. 5, p. 1269-1278, 2005.

LENARDÃO, E. J.; FREITAG, R. A.; DABDOUB, M.J.; BATISTA, A.C. F.S., DA CRUZ, C. "Green chemistry": Os 12 princípios da química verde e sua inserção nas atividades de ensino e pesquisa. Química Nova, São Paulo, v.26, n.1, p.123-129, 2003.

LIMA, V. L. A. G.; , MÉLO, E. DE A.,; GUERRA, N. B. (2007) Correlação entre o Teor de Antocianinas e Caracterização Cromática de Polpas de Diferentes Genótipos de Aceroleira, Brazilian Journal of Food Technology, v.10, n. 1, p. 51-55, 2007.

MACHEIX J.J; FLEURIT, A.; BILLOT, J. Fruit Phenolics. Boca Raton: CRC Press.,1990. 378p.
MARÇO, P. H.; POPPI, R. J., SCARMINIO, I. S. (2008) Procedimentos analíticos para identificação de antocianinas presentes em extratos naturais. Química Nova, São Paulo, v.31, n. 5, p. 1218-1223, 2008.

MELCHERT, W. R., ROCHA, F. R. P., JR, I. M. R., REIS, B. F. Construção de uma cela de fluxo de longo caminho óptico para medidas espectrofotométricas. Química Nova, São Paulo, v.31, n. 2, p. 427-429, 2008.

NUNES, G.; RIBEIRO, D.; SILVA, F. E. P. S.; CATANANTE, G.; MARTY, J.L. Determination of the Antioxidant Capacity of Red Fruits by Miniaturized Spectrophotometry Assays. Journal of the Brazilian Chemical Society, v.30, n. 5, p. 1108-1114, 2019.

R CORE TEAM. R: A language and environment for statistical computing. $\mathrm{R}$ Foundation for Statistical Computing, Vienna, Austria. 2020. Disponível: https://www.R-project.org/. Acesso em: 25 de mar. 2020.

TEIXEIRA, L. N., STRINGHETA, P. C., OLIVEIRA, F. A. (2008) Comparação de métodos para quantificação de antocianinas. Revista Ceres, Viçosa, v.55, n.4, p. 297-304, 2008.

YUANA J.; LIB, H.; TAOC, W.; HANA, Q.; DONGA, H.; ZHANGA, J.; JINGA, Y.; WANGA, Y.; XIONGA, Q.; XUD, T. An effective method for extracting anthocyanins from blueberry based on freeze-ultrasonic thawing technology. Ultrasonics Sonochemistry, v.68, p. 1-8, 2020. 